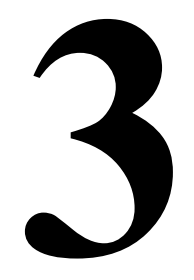

\title{
AVALIAÇÃO DIAGNÓSTICA \\ COMO INSTRUMENTO \\ DE APRENDIZAGEM NO \\ ENSINO FUNDAMENTAL EM \\ PRESIDENTE KENNEDY-ES
}

Cheila dos Santos Marvila
Luana Frigulha Guisso

\section{INTRODUÇÃO}

A avaliação escolar tem o intuito de fornecer aos professores informações sobre a aprendizagem dos alunos. O esperado é que os professores façam uso dos seus resultados para aprimorar sua didática, reorganizar seus planejamentos com a finalidade de colaborar com a aquisição de conhecimento por parte de seus alunos.

A avaliação diagnóstica tem como objetivo a melhora da assimilação do conteúdo, oferecendo informações essenciais para o aprimoramento dos conteúdos, envolvendo a coleta de dados, a qual auxilia no diagnóstico do processo de ensino e apredizagem. Tais informações propiciam aos professores o aprimoramento do planejamento, na perspectiva de conseguir maior eficácia na compreensão e assimilação dos conteúdos por parte dos alunos.

A avaliação diagnóstica é realizada mediante análise, síntese e contemplando-se pesquisas do conhecimento consolidado pelo aluno; a partir dos resultados, na premissa de se reformular novos caminhos e se reorganizar novas metodologias para que o discente possa reestruturar o próprio conhecimento e valer-se de suas habilidades (LUCKESI, 2011).

Em face a essa interposição, percebe-se que a avaliação é um processo contínuo, utilizado como mecanismo para se verificar o que o aluno aprendeu, na perspectiva de se adequar a metodologia para que haja uma aprendizagem satisfatória. Compreendendo-se que a função da avaliação é oportunizar o diagnóstico, na premissa de se buscar o aprimoramento do ensino e aprendizagem, sugere "que a avaliação é o termômetro para se confirmar o estado em que se encontram os elementos envolvidos no contexto de fixação do conteúdo, tendo, portanto, um papel significativo no processo educacional (SANT'ANNA, 2013,p.7).

A presente pesquisa debruçou-se na investigação das práticas avaliativas, a partir da análise de documentos e da elaboração de dados, atendo-se a observações e entrevistas, evidenciando os conceitos de avaliações aplicadas e suas respectivas finalidades. Desse modo, desenvolveu-se uma reflexão sobre avaliação 
diagnóstica aplicada em duas escolas, sendo as já referidas instituições, polos do ensino fundamental I do município de Presidente Kennedy/ES.

Há um enorme significado em se alcançar uma educação de qualidade no nosso país, sobretudo, em face às dinâmicas atuais, e às necessidades prementes de mudanças de paradigmas, no intuito a se romper o contexto de fracasso escolar. A urgência na oferta de um ensino de qualidade, com compromisso do desenvolvimento de uma formação, a qual permita ao discente alcançar o empoderamento social e a sua constituição como cidadão, está consolidada como necessidade, bem como a premissa de que este tenha assegurada a sua qualidade de vida, por meio da proteção aos direitos, valores éticos e sociais e singularidades.

Parte-se do pressuposto de que o aluno apresenta ao professor informações para que o mesmo faça o delineamento das metodologias de ensino e aprendizagem com a finalidade de alcançar a compreensão e o seu desenvolvimento. Nesse sentido Hoffmann (2007) afirma que:

Entretanto, apesar da importância do processo avaliativo na construção de uma educação de qualidade, esse aferimento envolve uma complexidade de dimensões e muitas questões, sobretudo, quando ela é entendida de forma contraditória, e passa a ser uma prática avaliativa improvisada e arbitrária. Quando a avaliação admite a função classificatória e burocrática, corre o risco de perder seu intuito principal, que é o de diagnosticar, formar e somar. Pensar sobre as práticas avaliativas, possibilita compreender, como a educação das crianças vem sendo refletida, por meio das administrações.

A pesquisa corrobora-se de grande relevância e justifica-se como significativa, a partir da proposta ensejada na investigação, que teve no seu escopo, a premissa de verificar com parte do corpo docente, professores regentes das séries iniciais do ensino fundamental, se o uso da avaliação diagnóstica, aplicada pelo município de Presidente Kennedy, contribui efetivamente no processo de aprendizagem dos alunos, e os interroga ainda acerca da geração de dados em consideração à busca pela qualidade do ensino.

O objetivo geral desta pesquisa é compreender de forma abrangente, a avaliação diagnóstica realizada pela Secretaria Municipal de Educação de Presidente Kennedy-ES, na intencionalidade de interrogar sobre a sua contribuição dentro do processo de alfabetização de alunos do Ensino Fundamental séries iniciais.

\section{O PROGRAMA SAÚDE NA ESCOLA (PSE)}

O percurso metodológico adotado para a presente investigação valeu-se da abordagem qualitativa, no intuito de analisar os questionários, e na busca por compreender as abordagens dos professores, bem como na descrição das ocorrências, do melhor modo possível. O procedimento metodológico tornou possível se lograr no aprofundamento do tema, e permitiu a escolha do trâmite mais eficaz para se trazer à tona a interpretação da realidade escolar.

A investigação foi realizada no ambiente escolar em duas escolas, como contexto de contemplação, observação, análise e julgamento, apontou como indispensável, imprescindível e imperativa, levando-se em conta a influência mútua de certos elementos contidos no estudo, a escolha também da modalidade de pesquisa qualitativa.

A presente pesquisa teve acrescido o aspecto descritivo, pelo fato de suscitar a compreensão, do percurso de avaliação diagnóstica do processo de ensino e de aprendizagem dos alunos no âmbito escolar. Os dados reunidos, ampararam as análises e, mediante o aprofundamento das respostas, tornou-se viável o 
entrecruzar da pesquisa bibliográfica, com a documental, e a descritiva, de modo a produzir-se dados para se consolidar a hipótese estabelecida.

Foram usados pseudônimos enumerados para preservar o anonimato dos participantes na pesquisa. Para uma melhor organização dos dados dividiu-se em dois grupos. O primeiro com os participantes da EMEIEF de Jaqueira "Bery Barreto de Araújo": PJ 1 (Professor 01); PJ 2 (Professor 02); PJ 3 (Professor 03); PJ 4 (Professor 04); PJ 5 (Professor 05); PJ 6 (Professor 06); PJ 7 (Professor 07); e o segundo com os participantes da EMEIEF "Vilmo Ornelas Sarlo": PV 1 (Professor 01); PV 2 (Professor 02); PV 3 (Professor 03); PV 4 (Professor 04); PV 5 (Professor 05); PV 6 (Professor 06); PV 7 (Professor 07); PV 8 (Professor 08).

\section{RESULTADOS E DISCUSSÕES - O PROCESSO DA AVALIAÇÃO DIAGNÓSTICA DA SEME/PK: Desenvolvidas pelo Projeto Kennedy Educa Mais}

A preocupação durante a análise realizada foi a de refletir, e analisar de forma cautelosa, as manifestações dos professores que participaram da pesquisa, tanto no que tange aos seus posicionamentos referentes a avaliação diagnóstica, como é compreendida na sua íntegra.

Aqui estão expostas as percepções, reflexões e debates dos professores acerca da avaliação diagnóstica, com a descrição de sua ocorrência e as contribuições para a educação do município de Presidente Kennedy-ES. Todavia, compreendendo a percepção e instrumentalização da avaliação diagnóstica na prática pedagógica dos professores.

A avaliação diagnóstica abordada como objeto de estudo foi o Simulado Municipal apresentado pelo do Programa "Kennedy Educa Mais que, em seu quarto ano de desenvolvimento, ofertando aos alunos da rede pública do município de Presidente Kennedy-ES, atividades integradas complementares ao currículo escolar, visa oportunizar a aprendizagem e ampliar a formação do discente com várias ações.

\subsection{A contribuição da avaliação diagnóstica ofertada pela Secretaria de Educação do Município de Presidente Kennedy-ES;}

Nesse ponto da pesquisa, foram examinadas as contribuições da avaliação diagnóstica ofertada pela SEME/PK, percebida nos relatos dos professores pesquisados da EMEIEF de Jaqueira "Bery Barreto de Araújo e da EMEIEF "Vilmo Ornelas Sarlo". Os dados foram analisados por escola e, em alguns momentos, estão agrupados para melhor compreensão. Para essa análise sobre a contribuição da avaliação diagnóstica ofertada pela SEME/PK, os professores foram questionados em 5 pontos diferentes:

$1^{\circ}$ ponto - A avaliação diagnóstica ofertada pela SEME/PK contribui para a melhoria do ensino? $2^{\circ}$ ponto- A utilização dos resultados da avaliação diagnóstica da SEME/PK ajuda no planejamento? $3^{\circ}$ ponto- A avaliação diagnóstica ofertada pela SEME/PK expõe pontos positivos e negativos na percepção do professor? $4^{\circ}$ ponto-Há uma assistência pedagógica para os alunos que não obtiveram bom desempenho 
na avaliação diagnóstica da SEME/PK? $5^{\circ}$ ponto- Há ações interventivas desenvolvidas após aplicação da Avaliação Diagnóstica pela SEME/PK?

$\mathrm{O} 1^{\circ}$ ponto - Questionou-se se a avaliação diagnóstica ofertada pela SEME/PK contribui para a melhoria do ensino, $72 \%$ dos professores concordaram plenamente com ela, $14 \%$ concorda, porém com alguma objeção, como a idealizada pelo PV1 "Poderia ser utilizada um pouco mais os resultados obtidos para intervenções efetivas com os alunos com dificuldades". Outros 14\% professores discordaram totalmente, justificada pelo professor PJ 4 "são pouco produtivas", e pelo PJ 5"pois não acredito que quantidades seja qualidade".

O uso da avaliação para fins de investigação e intervenção com mudança nas práticas de ensino nota-se no relato do professor PV 8 "uma vez detectado a defasagem podemos traçar novas estratégias de ensino". Do mesmo modo pelo professor PV 4 "as informações obtidas auxiliam a rede escolar para planejar intervenções para auxiliar o aluno na sua aprendizagem". Igualmente compreendida, agregando a contribuição do setor pedagógico escolar, presencia-se no relato do professor PV 5 "o professor juntamente com a equipe pedagógica pode traçar, elaborar mecanismo a serem inseridos em cada turma".

Para fins de cunho mais abrangentes, uma avaliação diagnóstica com ação interventiva desenvolvida pela SEME/PK, constata-se na transcrição do professor PV 7 “Tem proporcionado melhoria em materiais pedagógicos para os alunos, elaboração de estratégias como reforço escolar, formações docentes, unificação do currículo para rede municipal".

O $2^{\circ}$ ponto - Buscou-se a compreensão acerca do uso da avaliação diagnóstica, bem como de sua contribuição na verificação da aprendizagem, como investigação e intervenção. Procurou-se informação sobre a utilização dos resultados da avaliação diagnóstica aplicada pela SEME/PK para planejamento.

Ficou evidente que os professores da escola "Vilmo O. Sarlo" utilizam a avaliação diagnóstica tanto para a investigação como para intervenções. De positivo foi contatado que $100 \%$ deles utilizam a avaliação para planejar novas ações, como mostra o Professore PV 2 "observo o desempenho do meu aluno e traçar novas estratégias para ajudá-lo sanar as dúvidas". De forma muito similar o Professor PV 7 afirma a utilização planejar "verifico as dificuldades e vou retornando os conteúdos, fazendo um paralelo aquele que está sendo ensinado".

Na escola "Berry Barreto de Araújo" presenciou-se que 83\% dos Professores utilizam a avaliação para investigar e fazer intervenções, como coloca o Professor PJ 3 "sempre fazendo adequações necessárias para melhorar o desempenho da aprendizagem dos alunos". O Professor PJ 4 trabalha a avalição diagnóstica em menor intensidade que os demais companheiros afirmando que usa "mais ou menos, pego alguns pontos positivo e negativos que os alunos tiveram e trabalho". Compreende-se que o professor usa os termos "pontos positivos e negativos" para expressar as habilidades que os alunos já desenvolveram e as que ainda precisa desenvolver.

Nesse sentido, Hoffmann (2001) esclarece que a avaliação é uma ação continua, “[...] Todos os aprendizes estão sempre evoluindo, mas em diferentes ritmos e por caminhos singulares e únicos. O olhar do professor precisará abranger a diversidade de traçados, provocando-os a progredir sempre (HOFFMANN, 2001, p. 47).

De certa forma, compreende-se que os professores das duas escolas utilizam a avaliação diagnóstica como uma ação continua, traçando novas estratégia com os que não desenvolveram uma ou outra habilidade e para os que já alcançaram o aprendizado novos estimulo para aquisição de novos saberes. Então, 
conclui-se que a avaliação diagnóstica contribui para organizar e reorganizar novas práticas pedagógicas.

O $3^{\circ}$ ponto- Analisou-se também as contribuições da avaliação diagnóstica ofertada pela SEME/PK, segundo os relatos dos pontos positivos e negativos percebidos pelos professores pesquisados nas duas escolas lócus. Os dados e análise referente a essa questão foram tratados juntos.

Ponto negativos percebe-se que 11 dos professores ou seja 79\% queixam-se que a avaliação diagnóstica necessita de ajustes. Como o tempo de aplicação, tempo para as intervenções, textos com tamanho adequado a série/turma, discutir os dados levantamentos a ações a serem desenvolvidas e a diminuição do número de avalições no ano letivo e 3 professores equivalente a $21 \%$ não opinaram

Ponto positivos 7 professores igual a $50 \%$ se omitiram a opinar nessa questão. E os outros 7 professores igual a 50\% opinaram, compreendendo que a avaliação permiti a unificação dos conteúdos curricular da rede municipal, auxilia na detecção do nível de conhecimento dos alunos e planejamento das intervenções.

A avaliação diagnóstica aplicada pela SEME/PK, na visão dos professores tem pontos positivos e negativos. No entanto pedimos aos professores para elencarem os pontos positivos e negativos das avaliações (simulado municipal). Contudo percebe-se que as abordagens negativas foram bem superiores aos pontos positivos, onde 11 professores (79\%) queixam-se que a avaliação diagnóstica necessita de ajustes.

Foram feitas observações sobre a grande quantidade de avaliações, referindo se ao tempo de uma avaliação para a próxima ser muito curto, não permitindo ter eficácia todas intervenções, como percebe-se no relato dos professores PJ 1 "O tempo de aplicação, o tempo para rever os conteúdos não alcançados pelos alunos é muito curto". Também foi criticada pelo professor PJ 2 "Há necessidade de mais tempo para que a intervenções sejam aplicadas". "Tempo de aplicação e o tempo para rever os conteúdos não alcançados pelos alunos fica corrido."

Do mesmo modo foi criticada na escola "Vilmo O. Sarlo", dentada na transcrição da fala do professor PV 5 "a quantidade absurda que elas são aplicadas nas escolas", complementou-se com a fala do professor PV 7 "mais tempo para rever os conteúdos não alcançado pelo aluno e acaba sendo atropelado por outra".

Percebe-se a ausência de discussão dos resultados da avaliação diagnóstica pelos pedagogos escolares e pela SEME/PK, citada por dois professores, relacionando que sem esse fundamento a avaliação se torna desnecessária pela inexistência de intervenções externa. Como elucida o professor PJ 6“a discussão dos resultados não existe, é necessário discutir a partir dos dados levantamentos a ações a serem desenvolvidas, avaliar por avaliar não faz sentido". Também afirmada pelo Professor PV 8"não existe uma orientação ou fiscalização para melhora o ensino".

A abordagem crítica do professor PV 4 "analisar a avaliação como única medida para análise" resume-se que a avaliação em forma de simulado é incompleta. Uma avaliação mais complexa pode ser e percebida nas atividades lúdicas, coletivas, individuais, afetivas e criativas do cotidiano escolar. Valida observação do professor somada a percepção de Vasconcellos (2005, p.69) o papel da escola é buscar a formar cidadão pela mediação do conhecimento científico, estético, filosófico, onde desde de cedo o aluno precisa ser orientados para dar um sentido ao estudo, visando colocar a construção de um mundo melhor, mais justo e solidário.

Constatou-se que a avaliação diagnóstica ofertada pela SEME/PK tem o caráter fiscalizador do cumprimento do currículo municipal, percebido como um ponto negativo pelo professor PJ 6 “os simulados é uma estratégia viável para acompanhar o trabalho do professor e o desenvolvimento da turma. O que é inviável, ou desnecessário". 
Percebeu-se que a maioria dos professores transcreveram nos pontos negativos propondo novas adaptações para as próximas edições das avaliações diagnósticas aplicada pela SEME/PK. Sendo maior reivindicação atribuídas a um número menor de avaliações durante o ano letivo permitindo um tempo maior para as intervenções pedagógicas.

Os pontos positivos referentes a avaliação diagnóstica aplicada pela SEME/PK, no entanto 7 professores $(50 \%)$ se omitiram a opinar nessa questão. Dessa forma 7 professores $(50 \%)$ opinaram, compreendendo que a avaliação permiti a unificação dos conteúdos curricular da rede municipal, auxilia na detecção do nível de conhecimento dos alunos e planejamento das intervenções.

Dessa forma contatou-se que a SEME/PK não orienta os professores ou observa as necessidades dos alunos para melhora o ensino, como coloca o Professor PV 8, nos seus pontos negativos.

$\mathrm{O} 4^{\circ}$ ponto- $\mathrm{Na}$ análise das ações desenvolvidas pelos professores, pela escola ou pedido da SEME/ PK, como ação pedagógica/interventiva, fruto da investigação após a realização da avaliação diagnóstica (simulado municipal). No questionário, o participante poderia discutir abertamente sobre duas perguntas, a primeira é se recebe assistência pedagógica com os alunos que não obtiveram bom desempenho na avaliação diagnóstica? A segunda é se existem ações pedagógicos na escola com relações aos resultados das avaliações diagnóstica?

Nesse ponto da pesquisa verifica que Luckesi (2011, pag. 175), valoriza a avaliação da aprendizagem como investigação e intervenção. O objetivo é que nossos alunos aprendam e por aprender, se desenvolvem através da prática escolar.

Referente à primeira pergunta os professores da EMEIEF de Jaqueira "Bery B. de Araújo", que compreende o recebimento de assistência pedagógica com os alunos que não obtiveram bom desempenho na avaliação diagnóstica, $80 \%$ dos professores afirmaram que sim, 10\% nem sempre e $10 \%$ não. O sim que representa o auxílio do pedagógico na escola, em que o professor PJ1 atribui a ajuda para "formular de novas estratégias junto ao pedagogo". Os professores não justificaram as respostas nem sempre e o não recebimento de assistência pedagógica.

Os professores da EMEIEF "Vilmo Ornelas Sarlo", na primeira pergunta, não se obteve respostas muito diferente quanto a compreensão do recebimento de assistência pedagógica com os alunos que não obtiveram bom desempenho na avaliação diagnóstica, 75\% dos professores afirmaram que sim e $25 \%$ que não recebe assistência pedagógica. O sim que representa o auxílio do pedagógico na escola, em que o professor PV1confirma a contribuição "na escola o pedagogo sempre nos ajude com intervenções, troca de experiência".

O Professor PV 4 afirma que ocorre a ação interventiva em forma de reforço escolar para os alunos com mais dificuldade. Para a aula de reforço precisa se de outro professor, sala disponível no contra turno, transporte e uma série de outros fatores que envolve escola comunidade. Dessa forma compreende-se o posicionamento da SEME/PK como ação interventiva a parti da avaliação diagnóstica.

Os professores que se posicionaram sobre há não assistência pedagógica para os alunos que não alcançaram um bom rendimento expressam como quem esperava maior comprometimento tanto da escola como da SEME/PK da seguinte forma PV 6 "não, deveria ter maior atenção com os alunos de baixo rendimento" e o professor PV 8 "Não, Assistência não é realizada periodicamente”.

Buscou-se compreender junto os professores se existe ações pedagógicas na escola com relações aos resultados das avaliações diagnóstica. Essa questão é importante por proporcionar a compreensão do posi- 
cionamento tanto da SEME/PK quanto da escola para trato interventivo a parti do diagnóstico.

Constatou-se que 83\% dos professores da EMEIEF de Jaqueira "Bery Barreto de Araújo", julgam ter ações interventivas após resultados das avaliações diagnóstica, como reforço no contra turno para os que apresentaram resultados e certificados negativos os que conseguiram as melhores pontuação. Como afirma o professor PJ 4 "Sim, os reforços no contra turno para trabalhar as dificuldades". Verificou-se a existência de reforço escolar hipoteticamente pedido pela escola e ofertado pela SEME/PK e $12 \%$ ou seja 1 professor afirma que não tem ações interventivas. afirma o professor PJ 5 "não posso afirmar que o reforço escolar foi em decorrências os resultados dos simulados".

A resposta do professor PJ 6, compreendemos algumas ações interventiva proposta pela escola, "[...] o uso do caderno de reforço e mídias tecnológicas, como o whatsapp, para maior interação e aproximação com os pais e responsáveis. E Entrega de certificados para os alunos com melhor desempenho”.

As ações interventivas proposta pela SEME/PK foram detectadas nos relatos do professor PJ 1 "as intervenções existem ao decorrer do ano letivos através de intervenções pedagógicas, cursos, etc”. Neste caso quando o professor se refere a curso são capacitação ofertada pela Secretaria Municipal de Educação de Presidente Kennedy-ES.

No entanto, depara-se com uma resposta que pode ser entendida ou não como a denúncia uma ação escolar que não foi tomada democraticamente, onde não ficou claro os critérios para oferecer ao aluno com dificuldades o reforço escolar no contra turno, afirma o professor PJ 5 "não posso afirmar que o reforço escolar foi em decorrências os resultados dos simulados". Outra situação relevante foi a denunciada pelo professor PJ 2 “, as ações pedagógicas ficam focada nas atividades em que os alunos não estão bem”. Compreende-se nesse ponto uma maior preocupação em ofertar praticas interventivas para os alunos que apresentam dificuldades de aprendizagem.

A segunda questão levantada com os professores da EMEIEF "Vilmo Ornelas Sarlo", se existe ações pedagógicas na escola com relações aos resultados das avaliações diagnóstica. Esta questão aberta os professores responderam de forma espontânea. Onde 75\% deles delegam que existe intervenção sim, a partir dos resultados da avaliação diagnostica ofertada pela SEME/PK e 2 professores $25 \%$ afirma que não existem.

O professor PV 7 afirma a "contribuição da avaliação diagnóstica para adaptação de suas práticas de ensino como o recebimento de suporte externo como o reforço escola, "são encaminhadas atividades extras para casa, orientações aos pais, os alunos direcionados a aulas de reforços oferecidas pela SEME/ PK e podem contar com o professor auxiliar". Nesse caso constata-se uma intervenção diferente que é a inclusão do professor auxiliar. Compreende-se nesse ponto que a avaliação diagnóstica significa investigar e, com base nos conhecimentos, foram tomadas decisões de intervenção quando necessário.

O professor PV 1 relata o reforço escola como uma medida interventiva, "o reforço escolar e atividades diferenciadas de acordo com o desenvolvimento dos alunos". As atividades diferenciadas indicas uma sala com diferentes níveis de aprendizagem necessitando de diferentes planos de aula. Indicação do reforço escolar foi reforçada pelo professor PV 5, "aulas de reforços com os alunos que não obtiveram um resultado satisfatório”. Dessa forma avaliação diagnóstica, em si, é dinâmica e construtiva, a sua finalidade é oferecer suporte ao professor, tendo em vista uma aprendizagem efetiva do aluno.

Nessa questão que analisa a inserções de ações pedagógicas a partir da avaliação diagnóstica aplicada pela SEME/PK, dois professores (25\%) transcreveram que não existem. O professor PV 6 “o professor que 
comentar os resultados e tenta incentivar para melhoria na aprendizagem”. Foi constatado que não existe na sua turma intervenções por parte da SEME/PK, sendo o próprio professor junto com o pedagogo da escola buscam diagnosticar o conhecimento e subsidia as decisões. Por outro ponto de vista a turma pode ter um nível de conhecimento considerável que a aprendizagem já está satisfatória, nesse caso fica só para reorientá-la e novos estímulos.

De uma forma crítica sobre a inserções de ações pedagógicas a partir da avaliação diagnóstica aplicada pela SEME/PK, o professor PV 8 "não da parte da escola, mas em sala de aula, utilizamos recursos como apostilas, recursos pedagógicos para fazer os alunos alcançar os objetivos propostos”. Presenciou-se que o professor tece suas práticas educativas utilizando a avaliação diagnóstica e se lamenta a falta de auxílio do pedagogo da escola, trabalhando individualmente.

Enfim, compreende-se que uma avaliação diagnóstica aplicada pela SEME/PK que está a serviço do projeto de ação, como uma análise categórica da aprendizagem dos alunos a fim de diagnosticar impasses e, por conseguinte, propõem o reforço no contra turno para os alunos com dificuldade ou professor auxiliar para a turma.

\section{CONSIDERAÇÕES FINAIS}

Foi possível perceber o quanto avaliar é uma tarefa que exige técnica, conhecimento, sinceridade e comprometimento e muita responsabilidade para o professor, pois se torna difícil devido, ser concebida para aprovação ou reprovação, de forma classificatória nas escolas, e mudar essa realidade esbarra na resistência, tanto por parte do professor, quanto por parte da sociedade.

O ponto positivo da avaliação diagnóstica, a ação dos professores em repensar sobre a práticas pedagógicas dando aos alunos que ainda não desenvolveram as habilidades necessárias, maior atenção e orientação. Essa ação interventiva deve ser estendida a todos os professores através de uma formação continuada. De forma que todos compreendam a importância e o significado da avaliação diagnóstica como ação inovadora no processo de ensino e aprendizagem.

Verificou-se junto aos professores os instrumentos pedagógicos utilizados para avaliar a aprendizagem na perspectiva diagnóstica e as compreensões de avaliação diagnóstica. Os instrumentos avaliativos foram diversos somados as avaliações aplicadas pela SEME/PK. Onde constatou a ampla preocupação com a qualidade de ensino nas duas escolas.

Conhecer as diferentes compreensões de avaliação diagnóstica que os professores concebem nas práticas pedagógicas foi, muito relevante para esse estudo, pois se tornam fundamental para auxiliar na análise do posicionamento desses profissionais quanto a avaliação diagnóstica ofertada pela SEME/PK.

No entanto, foi preciso unir as concepções apresentadas pelos professores de avaliação diagnóstica para ter um sentido mais amplo. Seria interessante que a SEME/PK e as escolas passassem a incentivar a avaliação diagnóstica e que este tema se tornasse objeto de estudo, por meio de uma formação, a fim de que os professores trocassem experiências e ampliassem conhecimento, porque somente conhecendo o processo é que o docente pode compreender que a aplicação da avaliação diagnóstica é inerente a esse contexto de busca de maior qualidade na aprendizagem, corroborando para um acompanhamento mais sistemático do aprendizado. 
Para identificar as contribuições da avaliação diagnóstica ofertada pela SEME/PK, para a melhoria da qualidade do ensino no município, verificou-se com os professores como ocorrem suas ações pedagógicas, as atuações interventivas assistidas pela SEME/PK. No primeiro ponto foi detectado que todos professores julgam usar a avaliação diagnóstica para o desenvolvimento da aprendizagem do aluno, para detectar a defasagem, para planejar ações interventivas.

Dessa forma, considera-se que todo o processo que envolve o programa de Avaliação Diagnóstica da SEME/PK apresenta vários fatores que não colaboram no cumprimento dos objetivos dessas avaliações, de modo a que sejam alcançados plenamente. Os pontos que são maximizados como essenciais estão relacionados a grande quantidade de avaliações, à falta de suporte pedagógico, pouco tempo para as ações interventivas e a ideia de fiscalização quanto ao cumprimento do currículo a qualquer custo.

Por fim, compreende-se que a avaliação diagnóstica é um desafio que exige mudanças de paradigmas por parte do professor. As transformações solicitam muito estudo, reflexão e ação. Por isso, exigem do professor a busca pela inovação, e uma mudança na postura do docente, tanto em relação à avaliação diagnóstica, na sua integralidade, à educação e à comunidade local. Compreendendo por fim que o ato de avaliar é dinâmico, e está em constante transformação. Sendo assim é preponderante que o professor busque também se reinventar em consonância com os avanços no campo da educação, aprimorando suas práticas a cada avaliação, no intuito de buscar sua excelência como docente, cuja culminância se dá na efetivação da aprendizagem pelo discente. 


\section{REFERÊNCIAS BIBLIOGRÁFICAS}

HOFFMANN, J. Contos e contrapontos: do pensar e agir em avaliação. Porto Alegre: Mediação, 2007.

HOFFMANN, J. Avaliação mediadora: uma prática em construção da Préescola à universidade. Porto Alegre: Educação e Realidade, 1993.

INSTITUTO DE APOIO À PESQUISA E AO DESENVOLVIMENTO JONES DOS SANTOS NEVES. Dados municipais: Presidente Kennedy (versão preliminar). Vitória, 1999. 31 p. Disponível em: http://www.ijsn.es.gov.br/ ConteudoDigital/20120828_reglitoralsul.pdf>.Acesso em: 24 mar. 2020.

INSTITUTO CAPIXABA DE PESQUISA, ASSISTÊNCIA TÉCNICA, E EXTENSÃO RURAL. Programa de Assistência Técnica e Extensão Rural PROATER 2011-2013. Vitória, ES: 2011. Disponível em: <https://incaper. es.gov.br/media/incaper/proater/municipios/Caparao/Presidente_Kennedy.pdf $>$. Acesso em: 3 nov. 2019.

LUCKESI, C. C. Avaliação da aprendizagem escolar: estudos e proposições. 22 ed. São Paulo: Cortez, 2011.

Presidente Kennedy, LEI No 1303, DE 10 DE MARÇO DE 2017.disponivel em: http://legislacaocompilada.com.br/ kennedy/Arquivo/Documents/legislacao/html/L13032017.html.Acesso em 08/04/2020.

SANT’ANNA, I, M. Por que Avaliar? Como Avaliar? Critérios e Instrumentos. Petrópolis, RJ: Vozes, 2013.

VASCONCELLOS, C. S. Avaliação da aprendizagempráticas de mudanças: por uma práxis transformadora. 7.ed. São Paulo. Libertad. 2005. 